\title{
LOCATING PUBLIC SCHOOLS IN FAST EXPANDING AREAS: APPLICATION OF THE CAPACITATED P-MEDIAN AND MAXIMAL COVERING LOCATION MODELS
}

\author{
Rafael Cezar Menezes ${ }^{1}$ and Nélio Domingues Pizzolato ${ }^{2 *}$
}

Received April 20, 2012 / Accepted January 25, 2014

\begin{abstract}
The area of Guaratiba, in Rio de Janeiro, presents extraordinary population growth rates that exceed all other districts of the city. Moreover, the public investments underway, in view of the 2106 Olympic Games, are making the region even more attractive. Therefore, it is appropriate to suggest proactive measures to avoid the predicted collapse of several public systems among them the education system. This paper considers the projected population for the years 2015 and 2020 and, using various computing resources, specially the ArcGIS Network Analyst tool for measuring traveled distances, proposes locating new facilities with the Capacitated p-Median Model and with the Maximum Covering Location Problem, considering an ideal maximal home-school distance of 1,500 meters, but also evaluating longer distances. Both problems have been solved with AIMMS. The consideration of both models provides a constructive insight that certainly improves the implemented solution and favors the local community.
\end{abstract}

Keywords: school location, capacitated p-median model, maximal covering location problem.

\section{INTRODUCTION}

The depletion of urban areas in the municipality of Rio de Janeiro, circumscribed by wetlands, mountains and sea, has led to the occupation of hills and slopes, the migration to distant suburbs, and the formation of slums. It should be noted that historically the strong socio-economic inequalities in the country have forced large segments of the population to search for inventive forms of struggle for survival, among them the construction of houses in areas illegally occupied, both public and private. In the case of the periphery, as well as in the metropolitan areas, this phenomenon has occurred without proper urbanization and infrastructure planning, including sanitation, transportation systems, health, and education. In the case of education, typically deficient when offered to the poorest populations living in distant areas, the school teachers, who come from other social groups and are not local residents, tend to find it isolated, unattractive,

\footnotetext{
*Corresponding author

${ }^{1}$ Researcher, Pontifical Catholic University of Rio de Janeiro - PUC-Rio, RJ, Brazil. E-mail: rafaelcezar@puc-rio.br

${ }^{2}$ Associate Professor, Pontifical Catholic University of Rio de Janeiro - PUC-Rio, RJ, Brazil. E-mail: ndp@puc-rio.br
} 
and less motivating. Certainly, the recent country's economic rise, and its goal to satisfy various international standards, especially regarding sanitation, health, and education, has motivated the government to invest in the most needy populations. On the other hand, along the last decade, almost if not all socially marginalized segments have made significant progress in economical and social participation and have, therefore, expanded their expectations for social integration.

The Guaratiba Administrative Region lies on the outskirts of the city of Rio de Janeiro and was the one that proportionally showed the largest population growth in the entire city. In year 2000 this region had $66.53 \%$ more people than in the previous 1991 Census, while the city as a whole grew about $6.88 \%$ over the same decade. The yearly values along the last 9 years have been about $5.83 \%$ for the Region and $.74 \%$ for the entire city. This fact implies a huge challenge for the planning of public services such as schools, hospitals, garbage collection, water supply, waste water treatment, and so on, in order to effectively meet the needs of this growing population. It is estimated that the quickness of the settlement process will be maintained or even increase, given the widespread availability of public land in the area and the ongoing investments in transportation that will substantially benefit the region in view of the 2016 Olympic Games.

The referred area is currently under highly accelerated occupation as a result of the intense population growth process noted on the large West Zone of Rio de Janeiro. The territory is being developed over a marshy area that is suffering landfills and unplanned occupation which, sooner or later, however, shall receive satisfactory public services. This fast occupation stems from a combination of reasons. On the one hand, the varied factors that have propelled the development on the West Zone, such as industrial areas, business activities, expansion of the urban occupation, intense offer of services, have reflected all around and have attracted unskilled man power from all quarters of the country. On another hand, unoccupied land in Guaratiba, is mostly property of the federal government, but the usual public policy is to tolerate illegal occupation, if no significant threat to the environment is perceived. Since this is the case, and housing for large segments of low income workers is at stake, these settlements are being progressively incorporated to the city. Finally, the current public investment plans on infrastructure and transportation, designed to satisfy the agreements for the 2016 Games, have determined the construction of a new Bus Rapid Transit (BRT) line that passes through the area and this is stimulating an even faster occupation.

The present settlement process has resulted in six nucleus or, more properly, six independent areas of occupation, connected by long sinuous roads, and served by a poor transportation system. At different paces, each one of these nucleus is continuously receiving new settlers and facing a dramatic expansion. As a consequence, any study in the area shall be composed by six similar studies applying similar methodologies. Given these evidences it is appropriate to suggest proactive measures to avoid the predictable collapse of the basic education system.

Using both the Capacitated p-Median Problem (CPMP) and the Maximal Covering Location Problem (MCLP), the objective of this work is to contribute to the planning of the public school network in this region, considering the forecast of strong population growth for years 2015 and 2020 as released by the IBGE Census Bureau (Brazilian Institute of Geography and Statistics). The former model seeks to minimize distances traveled by the students, taking into account 
the capacity of schools, which are being set to 1,300 students according to the recent policy of constructing standard sized schools. In the latter model the objective is to locate new schools seeking to maximize the number of students covered by the school network, according to a maximum given distance along the road network. The maximum distance would ideally be 1,500 meters but longer distances have been considered since they might be eventually required, unless many more schools are constructed. Precise distance measurements might be done with the ArcGis Network Analyst, a tool belonging to the family of Geographic Information Systems (GIS). Both models are subsequently solved with the Advanced Interactive Multidimensional Modeling System (AIMMS).

Thanks to the geographic tools included in the study, the ArcView Network Analyst in particular, the definition of school coverage areas is defined. The reach of each school might preferably be 1,500 meters, but could have different values, such as 1,000, 2,000 or 3,000 meters around each school, measured along the local road network, adjusted to any existing barrier or alternate paths. Certainly, long distances between a student and its school are not desirable but might be required. The mentioned ArcGis Network Analyst tool allows identifying the demand for each school within each distance level, warranting the suggestion to build new schools such as to reduce distances for all students to satisfactory levels.

Although both studies are concerned with the location problem, they have complementary features, and the corresponding data set vary according to the model applied. For the CPMP they represent the distance traveled by the student to the nearest school, while for the MCLP they indicate the school reach or distances measured from each school. In other words, the CPMP locates schools in order to minimize the sum of the distances traveled by all students but respecting the design capacity of 1,300 students, and the MCLP locates schools in order to maximize the number of students covered within a given distance. We understand that both models provide complementary information to be used in the planning process. Certainly, from the students or their families' point of view the actual selection process is more complex because it involves not only quantitative but also qualitative issues. However, if all schools have similar characteristics such as quality of the building, comfort, satisfactory school meals, experienced teachers, and so on, there will be no reason for the student to prefer a more distant school, since no bus service is provided. This study will also argue that as the CPMP model is successively applied for a growing number of schools the capacitated model will approach the MCLP solution.

Both studies have a normative character, since the city administration is the only supplier of education in the area, contrasting with most of other cities in the country in which private schools account for a significant part of the demand, typically one third. The reason is that the private schools are directed to specific social segments normally with higher income levels, but the average income observed in the area is presently a deterrent to private services.

This work is divided as follows: Section 2 makes a literature review on the location of schools and other public facilities; Section 3 briefly describes some functions of the ArcGis Network Analyst system. Section 4 introduces the mathematical formulation of both CPMP and MCLP models. Section 5 discusses the methodology employed, assessing the current distribution of 
Municipal Schools and proposing the location of new school facilities with respect to both models, given the demographic projections and the various options of maximum distance. Section 6 evaluates the conclusions and the contributions of the study.

\section{LITERATURE REVIEW}

The use of models to locate facilities supported by Geographic Information Systems (GIS) has become a powerful tool for the decision making process. The GIS graphical user interface associated with geo-referenced databases enables the public manager to prepare the location planning of the community facilities through the spatial analysis of a given area, taking into account the street configuration, geographical and topological barriers, as well as the distribution of the population by age, family income, family size, available areas, socioeconomic aspects, and eventual restrictions.

Regarding the location of public schools, an early and celebrated paper was published by Tewari \& Jena (1987). Using the tools available at the time, these authors study the high-school location problem in a large geographical district in India with two cities, hundreds of villages, more than 1.5 million inhabitants and propose the location of high schools considering, among others features, some peculiar questions such as the language spoken in each school and the maximum distance of $8 \mathrm{~km}$ for a student to reach a high school. This work was followed by many others such as Viegas (1987), Molinero (1988), Beguin et al. (1989), Pizzolato \& Silva (1997), Barcelos et al. (2004), Teixeira \& Antunes (2008), and so on.

In a recent study, White et al. (2010) review the use of optimization techniques in locating facilities in developing countries, highlighting a number of studies specially related to health and education. According to them, Rahman \& Smith (2000) provide a review of locational analysis for healthcare planning in developing countries; Galvão et al. (2002) apply locational techniques to optimize maternal and perinatal healthcare services in Rio; Pizzolato et al. (2004) consider the location of public schools in urban areas; Yasenovsky and Hogdon (2007) apply locational analysis to healthcare provision in the rural area of Suhum, Ghana; as well as Smith et al. (2009) that deal with a similar healthcare problem for rural regions of India. Another recent review on location challenges mostly based on the p-median model and extensions may be found in Pizzolato et al. (2012), as well as a hierarchical study on hierarchical location mostly directed to health services, may be found in Smith et al. (2013).

Considering the accessibility to schools through the maximal and ideal student-school distance, Brau et al. (1980), certainly influenced by European standards, suggest some ideal distances, which are not discrepant to those applied to urban areas in Brazil. These certainly differ substantially from the distances established by Tewari and Jena and employed in rural India, since a high school student in a rural area has larger walking autonomy than a young student in an urban setting. For childhood and elementary education, Brau et al. classify a distance of 500 meters between home and school as excellent accessibility, between 500 and 1,000 meters, as good accessibility, between 1,000 and 1,500 meters, regular accessibility, between 1,500 and 2,000 meters, low accessibility, and distances above 2,000 meters were classified as poor accessibility. The present study may face the maximum distance as a variable to be adjusted according to managerial preferences. 


\section{GEOGRAPHIC INFORMATION SYSTEM - ArcGIS NETWORK ANALYST}

ArcGIS is the name of a family of software produced by the ESRI Company. ArcGIS includes: ArcReader, which views maps created with other ArcGIS products such as ArcView for the visualization of spatial data, creation of maps and basic performance of spatial analysis; and ArcEditor, which includes all the functionality of ArcView and even more advanced tools for manipulating shapefiles and geodatabases. ArcInfo, the most advanced version of ArcGIS, includes additional capabilities for data manipulation, edition and analysis.

ArcGIS Network Analyst is an ArcGIS extension that allows performing a spatial analysis of the network, including routing between nodes, location and allocation of facilities, and definition of service area, among others. One of the major advances of the tool is the possibility of using the actual condition of the road network such as direction, speed limits, and blocks of any kind. Regarding the school location problem, this tool allows the practical consideration of distances along the road network, not only the minimum distances to use in the CPMP problem, but also the maximum distances to use in the MCLP problem. In this latter problem, the covering distance indicates the desired accessibility and may be exploited in a sort of sensitivity evaluation of the proposal for varying values of the distance.

The ArcGIS Network Analyst allows the generation of a series of polygons representing the distance that can be reached by a facility in relation to a maximal distance or time limits, using the road network of the study area. The polygons around each school are known as coverage area. Thus, it is possible to know the number of potential users who are within the pre-established coverage area, and the facilities that should be relocated to better serve them. This study used this tool to generate a series of tables containing the distance across the road network between a source vertex and several destination vertices, comprising the OD distance matrix. Due to space limitations, just one of the six areas, namely the Assessment Region 5, will be reported since this appears to be the most critical area of the region and representative of the entire study. In any case, the results for all Regions are available with the authors.

\section{CAPACITATED p-MEDIAN PROBLEM MODEL (CPMP)}

Given a network $\mathrm{G}(\mathrm{V}, \mathrm{A})$ consisting of a set $\mathrm{V}$ of vertices and a set $\mathrm{A}$ of arcs, the objective of the $\mathrm{p}$-median problem is to locate $p$ facilities in order to minimize the sum of weighted distances from each vertex to the nearest facility. The Capacitated p-Median Problem (CPMP) corresponds to cases where, for each facility $j$, there is a maximum capacity. The CPMP formulation derives from the p-median model (Current et al., 2002):

$$
\begin{aligned}
\text { Min } & Z=\sum_{i \in N} \sum_{j \in N} w_{i} d_{i j} x_{i j} \\
\text { Subject to } & \sum_{j \in N} x_{i j}=1, \\
& \sum_{j \in N} x_{j j}=p
\end{aligned} \quad i \in N
$$




$$
\begin{array}{ll}
\sum_{i \in N} w_{i} x_{i j} \leq Q_{j} x_{j j}, & j \in N \\
x_{i j} \in\{0,1\}, & i, j \in N .
\end{array}
$$

where:

$N=\{1,2, \ldots, n\}:$ set of demand points;

$N=\{1,2, \ldots, n\}:$ set of possible locations;

$w_{i}$ : weight at point or vertex $i$;

$p$ : number of facilities to be located;

$d_{i j}=$ shortest distance from vertex $i$ to vertex $j$;

$x_{i j}=1$, if demand point $i$ is served by facility located at vertex $j ; 0$ otherwise;

$x_{j j}=1$, if a facility is located at vertex $j ; 0$ otherwise.

The objective function (1) consists of minimizing weighted distances from each vertex to the nearest median; the constraint (2) requires that each vertex is allocated to a single vertex, which must be a median; the constraint (3) determines the exact number $p$ of medians to be located; and the constraint (5) specifies the integrality conditions. The formulation of the capacitated pmedian problem differs from the basic formulation of the $\mathrm{p}$-median problem with respect to the constraint (4), linking the customer $i$ to facility $j$, since this case considers the service capacity $Q_{j}$ of facility $x_{j j}$. The above model assumes, for each centroid, exclusivity with the facility that will offer the service, since the variables $x_{i j}$ are binary.

It is important to remark that the feasibility of the solution depends on the correct choice of the minimum value of the parameter $p$, since the total capacity offered has to meet the total population to be attended. The statement is more obvious when the schools have limited and similar capacities. In addition, as the number of schools increases, the average distance crossed by each student diminishes, although some of the schools might operate below their capacities.

\subsection{Maximal Covering Location Problem (MCLP)}

The MCLP consists of choosing locations to build $p$ facilities in order to cover the largest number of customers or users, since the coverage of a client means that its distance to a facility is less than a pre-established critical distance $(S)$. The model also identifies the allocations, i.e., in which facility each customer would be attended. Therefore, the aim is to maximize the coverage of a given population in relation to a given set of community facilities, and a given coverage radius, seeking to ensure that the greatest possible number of users is covered, while any user beyond the critical distance is no longer covered by this facility. The decision variable is basically the acceptable distance between the location of the service and the one of its customers.

Therefore, in the MCLP, the problem aims to locate $p$ facilities so that there are as many users as possible within the maximal predefined distance $S$. In some applications, this critical distance $S$ might be seen as a convenience parameter, in which smaller values are more desirable. Certainly, the quality of a given set of locations might be measured by the number of students living beyond 
the maximal distance. The formulation was first proposed by Church \& ReVelle (1974) and corresponds to the model:

$$
\begin{array}{rlr}
\text { Max } & Z=\sum_{i \in I} w_{i} z_{i} & \\
\text { Subject to } & \sum_{j \in N_{i}} x_{j}-z_{i} \geq 0, & \\
& \sum_{j \in J} x_{j}=p & \\
& x_{j} \in\{0,1\}, & j \in J \\
& z_{i} \in\{0,1\}, & i \in I .
\end{array}
$$

where:

$I=\{1,2, \ldots, n\}:$ set of demand points;

$J=1,2, \ldots, n\}$ : set of possible facilities;

$w_{i}$ : weight at point or vertex $i$;

$p$ : number of facilities to be located;

$d_{i j}=$ shortest distance from vertex $i$ to vertex $j$;

$N_{i}=\left\{j \in J \mid d_{i j} \leq S\right\}$, indicates the set $J$ of vertices that cover vertex $i$, i.e., all vertices $j$ for which $d_{i j}=S$ where $S$ is the maximal distance;

$z_{i}=1$, if demand point $i$ is covered; 0 otherwise;

$x_{j}=1$, if a facility is located at vertex $j ; 0$ otherwise.

The objective function (6) maximizes the covered demand within the stated maximal distance; the constraint (7) indicates that a customer will be covered if there is at least one facility located within the maximal coverage distance $S$. The constraint (8) limits to exactly $p$ the number of facilities located and the restrictions (9) and (10) define binary-type decision variables.

Regarding the influence of the parameter $p$, similar considerations might be done. A small value of $p$ might leave many students out of any school reach and the demand for the most central schools extremely high. In contrast, if $p$ is made progressively higher, all students would be attended but the school occupation would be highly uneven and some would have low demand.

\section{METHODOLOGY}

Figure 1 gives an overview of the Guaratiba region, indicating the location of the present 22 basic schools. The capacities are highly different since the capacitated schools is a policy recently implemented. Thus, capacities are known, but only partially reproduced on the forthcoming tables since this report intends to highlight only part of the district. In this figure, the road network as well as the present location of each school are represented. The size of each school according to three different capacity ranges is indicated by gray variations. Interested readers might ask the authors for a colored version of the figure. At the time of the study, 20,659 students were enrolled in these schools. The study conducted by the IBGE in 2004 - Demographic Trends in the 
City of Rio de Janeiro - based on the 2000 Census, estimated a population growth in Guaratiba of $75 \%$ until 2015, projecting 47,764 school-age children, and $4.75 \%$ growth per year between 2015 and 2020, and an estimated 60,238 school-age children at the end of that period. Thus, the forecasted scenario implies a significant shortage of places in public schools, if a vigorous program of building new schools is not implemented.
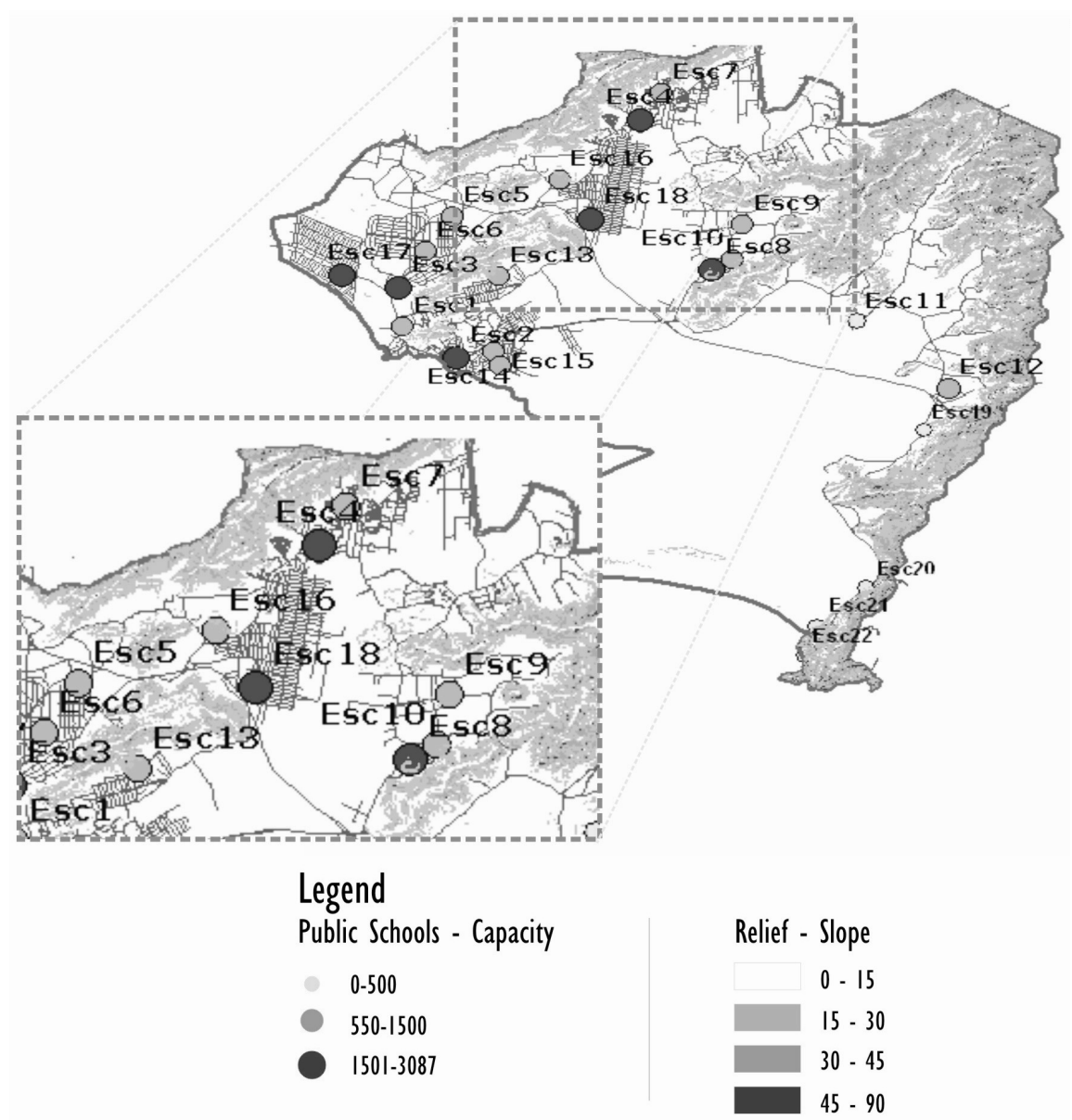

Figure 1 - Location and capacity of the public schools.

The distance home-school crossed by each individual student requires his precise residence address, but this information is not available. In order to overcome this impossibility, distances from each centroid to its closest school have been determined. These distances along the road network were calculated through the ArcGIS Network Analyst tool, from every centroid representing each census tract area to each school, while every student residing in a particular census area was supposed to live precisely on its centroid. This is an usual and reasonable approximation in urban studies, where all census areas involve small areas. 


\subsection{Assessment of the current location of Public Schools}

The Service Area tool of the ArcGis Network Analyst allowed constructing accessibility tracks around each public school. Figure 2 shows the accessibility tracks for the entire district studied, but highlights the Assessment Region 5, which is the one with the greatest imbalances. The figure also shows, around schools, colored areas representing different distances, based on the current street network around each school. Distances of 1,000, 2,000 and 3,000 meters are measured according to the road network, but the potentially desirable situation would be the concentration of these circles in distances of up to 1,000 or 2,000 meters between each student and the nearest school. Interested readers might ask the authors for a colored version of the figure.

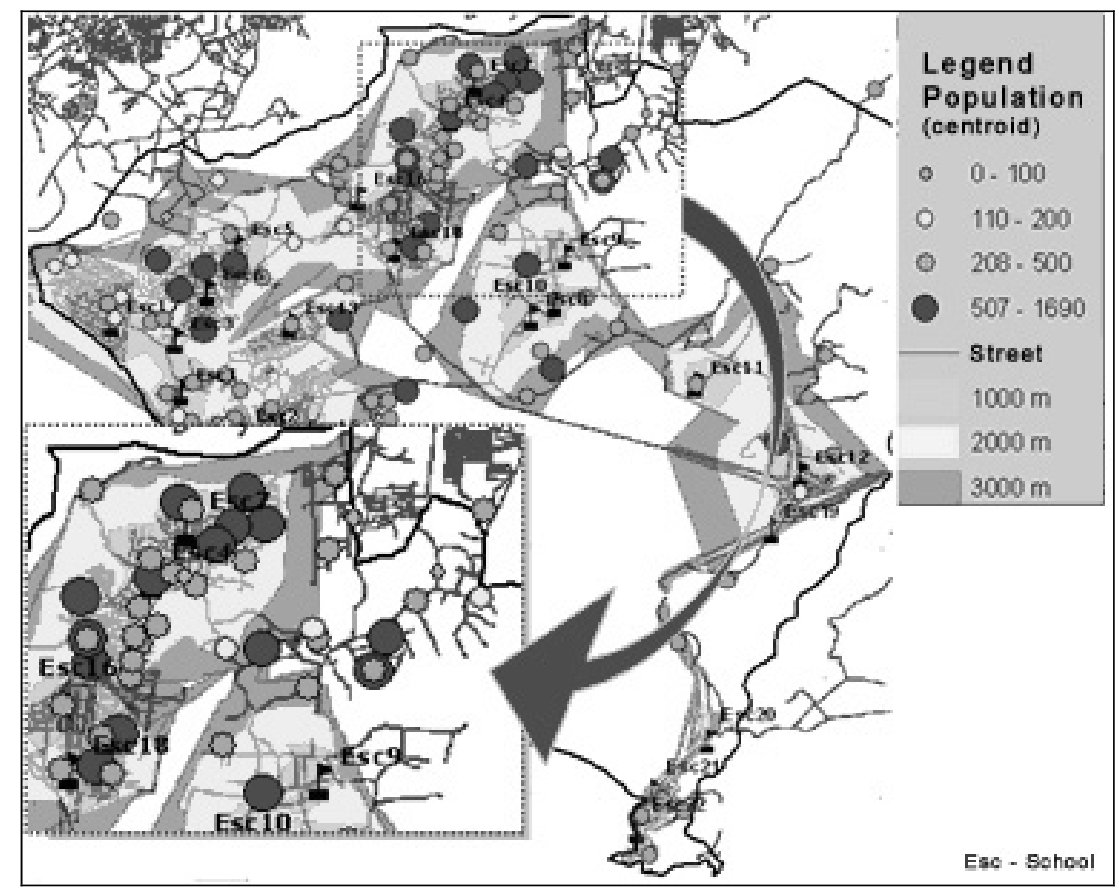

Figure 2 - Reach of the public schools.

Small circles of different colors represent the projection of the school-age population for the year 2015 in the centroid of each area. Circles of different gray intensity show the concentration of school population. Again, interested readers might ask the authors for a colored version of the figure.

It could be inferred that, for the years 2015 and 2020, a large concentration of school-age students will be found at shorter distances. Furthermore, a significant portion of the school-age population will be living at larger distances, showing an undesirable situation.

In the most critical case highlighted in Figure 2, the circles found beyond the larger schools, corresponding to the census tracts of large and intermediate sizes, represent school-agelocated 
more than 3,000 meters away from the nearest public school, featuring an improper situation. Certainly, the recommended proposal would be the construction of one or more new schools in the region in order to reduce the large distance to be covered by this part of the population.

It can be seen in the highlighted portion of the larger tracts (from 507 to 1,690 school-age people) or smaller ones (from 208 to 500 school-age people) have a school nearby (up to 1,000 meters) or as near (1,000 to 2,000 meters) as it is the case of schools 4, 7, 16 and 18, also belonging to the referred region. In any case, this is a region with insufficient coverage, since a significant portion of students is within the low accessibility zone or even beyond the desirable nearby zone.

\subsection{Location of New School Facilities under both Models}

The most recent schools that have been built in the municipality of Rio de Janeiro had a standardized service capacity of about 1,300 students. In the CPMP study it is assumed that new schools will be built according to this standard capacity, while pre-existing schools will keep their original capacities.

The goal of the second model, MCLP, is to determine the location of new facilities in order to maximize the number of students that might reach one school within a given radius, which is the maximum distance considered appropriate for the daily home-school travel of each student. Thus, the capacity of the new facility should be adjusted according to the total population to be covered. In this maximal covering model, population projections for the coming years were calculated, and the total capacity of the public school system had to satisfy all demand. Therefore, for this part of the study, the schools will be supposed uncapacitated.

Although both models appear independent, their joint consideration provides a constructive insight for implementing a solution that favors the population of the area, since capacity and distance may be balanced. The potential interrelation of these models are explored in the following pages.

Both models were solved in the AIMMS software, which features specific functionalities to model integer linear programming problems, providing various solvers and allowing the control of the performance of each. In this study, for its notorious advantages, the CPLEX solver was used to solve both of them.

\subsection{Results obtained with the CPMP}

Presently, there are four public schools in Assessment Region 5, namely, Sch4, Sch7, Sch16, and Sch18, as shown in the highlighted part of Figure 2 and their present combined capacity is 5,778 students. Incidentally, as shown in Table 3, if a coverage radius of 1,500 meters is set, only $55 \%$ of the school population that lives today in this region would be within this given range. Since the projected school-age population for 2015 is 19,295, the minimum number of new standard schools is 11, but we preferred to use the next integer, 12 schools. For 2020 a similar computation suggests the construction of three additional schools. 
The results obtained with the CPMP are summarized in Tables 1 and 2, the former referring to population projections for 2015 and the latter referring to year 2020. Thus, for the year 2015, the optimal sites to receive new educational facilities are the centroids corresponding to pop54, pop61, pop26, pop52, pop63, pop66, pop70, pop59, pop77, pop72, pop84, and pop86, considering the 1,300 students fixed capacity. For the year 2020, besides the twelve new schools, three additional schools should be built in centroids pop62, pop46, and pop56, in order to accommodate all students in the fixed-sized schools.

Table 1 - Location/Allocation of the Schooling Population to Public Schools in 2015.

CPMP Model: Assessment Region 5

\begin{tabular}{|c|c|c|c|}
\hline $\begin{array}{c}\text { Existing/ } \\
\text { proposed schools }\end{array}$ & $\begin{array}{c}\text { Population } \\
\text { to be served }\end{array}$ & $\begin{array}{c}\text { Population: } \\
\text { Projection 2015 }\end{array}$ & Capacity \\
\hline Sch4 & $50,87,89,92$ & $1,153.81$ & 1155 \\
\hline Sch7 & 48,79 & 815 & 816 \\
\hline Sch16 & $51,75,91$ & 717.23 & 720 \\
\hline Sch18 & $22,25,45,60,65,85,88,90$ & $3,083.05$ & 3087 \\
\hline pop54 & 47,54 & 923.04 & 1300 \\
\hline pop61 & $61,62,64$ & $1,234.88$ & 1300 \\
\hline pop26 & 26,49 & 941.75 & 1300 \\
\hline pop52 & 46,52 & $1,251.51$ & 1300 \\
\hline pop63 & $56,57,63$ & $1,180.83$ & 1300 \\
\hline pop66 & 66,68 & 883.54 & 1300 \\
\hline pop70 & $58,69,70,73$ & $1,291.01$ & 1300 \\
\hline pop59 & 59,71 & $1,112.23$ & 1300 \\
\hline pop77 & 76,77 & $1,278.54$ & 1300 \\
\hline pop72 & 72,74 & $1,189.15$ & 1300 \\
\hline pop84 & $44,78,83,84$ & $1,189.15$ & 1300 \\
\hline pop86 & 82,86 & $1,049.86$ & 1300 \\
\hline
\end{tabular}

For each year, both tables indicate the location-allocation result given by the model. On both tables the four first lines refer to the existing schools and also indicate the census tracts they attend, the projected population for the corresponding year, and their present capacity. For the additional lines, the tables indicate the location of the proposed school, the census tracts allocated to each, the projected population of each centroid, and the projected capacity. To exemplify, consider the first row of Table 1, in which it is expected that Sch4, maintaining its current capacity of 1,155 students, has enough places to serve the expected 1,153 students in 2015 and that these students might be those living in census tracts associated to centroids pop50, pop87, pop89, and pop92. In another example, in the fifth row of Table 1, the school proposed for centroid pop54 must meet the 923 students expected for centroids pop47 and pop54, while its capacity shall be 1,300 students. 
For the year 2020, a similar configuration was developed, as shown in Table 2 which has three more lines than the previous table. The explanation is similar to the one made above and both proposals provide elements to public managers to make the planning of school construction for the coming future. Certainly, the existence of more schools, eventually built for satisfying 2015 requirements, would change the allocation proposal for 2020.

Table 2 - Location/Allocation of the Schooling Population to Public Schools in 2020.

CPMP Model: Assessment Region 5

\begin{tabular}{|c|c|c|c|}
\hline $\begin{array}{c}\text { Existing/ } \\
\text { proposed schools }\end{array}$ & $\begin{array}{c}\text { Population } \\
\text { to be served }\end{array}$ & $\begin{array}{c}\text { Population: } \\
\text { Projection 2020 }\end{array}$ & Capacity \\
\hline Sch4 & 60,79 & $1,151.00$ & 1155 \\
\hline Sch7 & 65,90 & 813 & 816 \\
\hline Sch16 & 22,87 & 718.39 & 720 \\
\hline Sch18 & $25,48,51,82,89,92$ & $3,064.96$ & 3087 \\
\hline pop54 & 47,54 & $1,164.11$ & 1300 \\
\hline pop62 & 61,62 & 991.65 & 1300 \\
\hline pop26 & 26,49 & $1,187.70$ & 1300 \\
\hline pop52 & 52,64 & $1,266.36$ & 1300 \\
\hline pop46 & $46,50,57$ & $1,227.03$ & 1300 \\
\hline pop56 & $56,58,63$ & $1,284.71$ & 1300 \\
\hline pop66 & 66,68 & $1,114.29$ & 1300 \\
\hline pop59 & 59,75 & $1,266.36$ & 1300 \\
\hline pop76 & 70,76 & $1,292.58$ & 1300 \\
\hline pop77 & 73,77 & $1,297.82$ & 1300 \\
\hline pop74 & $71,74,91$ & $1,250.63$ & 1300 \\
\hline pop72 & 69,72 & $1,284.71$ & 1300 \\
\hline pop45 & 44,45 & 954.36 & 1300 \\
\hline pop84 & 84,85 & $1,229.65$ & 1300 \\
\hline pop86 & $83,86,88$ & $1,282.09$ & 1300 \\
\hline & & & \\
\hline & & & \\
\hline
\end{tabular}

In this case, two situations should be considered by the decision maker: First, if the proposals for 2015 are implemented the proposals for 2020 might be slightly different since new schools would have been constructed; otherwise, if proposals for 2015 are not implemented we would suggest to simply implement the solution suggested for 2020.

It is relevant to note that for both years 2015 and 2020, the model ought to use the full capacity of 1,300 students in each candidate site for receiving a new educational unit, accepting in some cases a slight excess of school places, or otherwise unused capacity, which is also admissible, in order to follow the stated fixed-capacity constraint. 


\subsection{Results obtained with the Maximal Covering Location Problem (MCLP) Model}

The MCLP is concerned with the maximum distance between a student and its closest school. The model disregards school capacities and turns out to be uncapacitated. The projections for year 2020 have been studied and the results are summarized in Table 3.

Table 3 - Location of New Schools - Year 2020 Maximum Covering.

Assessment Region 5

\begin{tabular}{|c|c|c|c|}
\hline $\begin{array}{c}\text { Existing/ } \\
\text { proposed schools }\end{array}$ & $\begin{array}{c}\text { Maximum } \\
\text { covering }\end{array}$ & $\begin{array}{c}\text { Covered } \\
\text { population } \\
\text { Projection 2020 }\end{array}$ & $\begin{array}{c}\text { Necessary } \\
\text { capacity } \\
\text { increment }\end{array}$ \\
\hline Sch 4, 7, 16, 18 & $55 \%$ & 13,689 & 7,911 \\
\hline Additional schools & & & \\
\hline pop 46 & $75 \%$ & 18,552 & 5,163 \\
\hline pop 84 & $86 \%$ & 21,433 & 2,581 \\
\hline pop 91 & $90 \%$ & 22,340 & 907 \\
\hline
\end{tabular}

Considering the estimated population for 2020, interesting results may be found. Presently, in the Assessment Region 5, as already mentioned, only 55\% of the population is reachable within a radius of 1,500 meters from a public school. The construction of a new school unit with capacity 5,163 students at the centroid corresponding to pop46 would increase this coverage to $75 \%$, and reach as many as 18,552 students. An additional school at centroid pop84 with capacity 2,581 students would increase the coverage to $86 \%$, with 21,433 people attended, and a third school with capacity 907 in pop91 would increase to $90 \%$ the population attended, comprising 22,340 students. Clearly, the MCLP model improves the accessibility but requires large capacities and expansion of the existing schools. Table 3 illustrates this analysis, in which the last column shows the additional capacity increment required to meet the defined goal.

The results indicate two severe limitations for the MCLP model. The first is that the model does not consider allocating the whole universe of students to schools, and second is that the proposed schools might be too large and beyond the pedagogical standards. Therefore, the MCLP should not be strictly applied but rather consider additional information such as those given by the CPMP model.

In general, if no action is taken, the difficulties observed in Assessment Region 5 will be related to both the service capacity of existing public schools, because they will be unable to support the growth of the schooling population in the coming years, and also in relation to the distance traveled by the students, because a larger proportion of students will be living in areas of lower accessibility. 


\subsection{Evaluation of Conjoint Results}

Figure 3 shows the results of the CPMP and MCLP models for Assessment Region 5, which are geo-coded in the digitalized map. Circles are used to represent locations eligible to receive a new school facility through the CPMP model in year 2015, and other circles contemplate the MCLP model, which seeks to meet as many users as possible with information from the year 2020. Interested readers might ask the authors for a colored version of the figure.

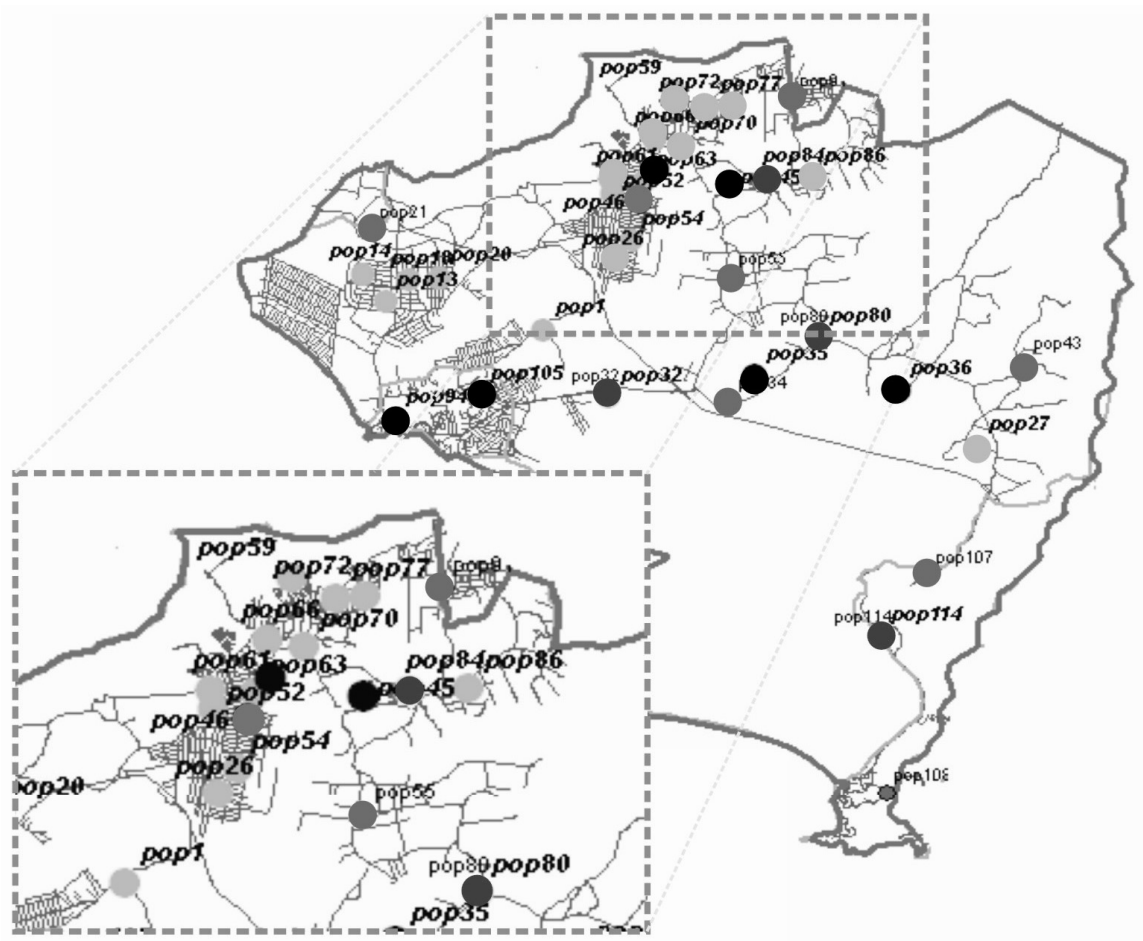

\section{Legend}
Results - MCLP
- Results - PMC (2020)
Results - PMC (2015)

Results - PMC and MCLP (2015)

Results - PMC and MCLP (2020)

Figure 3 - Location of the new school facilities.

The circles represent centroids where the results of the models coincided in 2015 with pop80, pop84, and the circle in 2020, around pop46, meets both the conditions for minimizing the average distance traveled by the students, and to cover the largest possible number of students within a radius of 1,500 meters. These three sites could be considered eligible to receive a new public school. Interested readers might ask the authors for a colored version of the figure. 


\section{FINAL CONCLUSIONS AND CONSIDERATIONS}

The results obtained with CPMP and MCLP models showed that, if the growth forecast predicted by the IBGE for the Guaratiba Administrative Region for the years 2015 and 2020 is confirmed, the number of school places available today in the public schools may be very inadequate, and serving the school population at a suitable distance could become an important factor to improve the usual low quality of the educational services.

In the Assessment Region 5, the CPMP location/allocation model showed that the construction of 12 standard Public Schools in 2015 with 1,300 students capacity and additional three for 2020 would be required to fully meet the expected population growth. For the entire district of Guaratiba these numbers would be 21 and seven, respectively.

The Maximal Covering model, MCLP, is primarily concerned with the location of school units to ensure the greatest possible number of school-age population within a radius of 1,500 meters from schools. However, guaranteeing this level of service can impose the construction of very large buildings, and disregard the complete universe of students, as discussed in Section 5.4. Overall, twelve public schools should be built in the entire Guaratiba Administrative Region to meet at least $90 \%$ of the population within the desired distance, while for the Assessment Region 5 three schools would be sufficient.

Despite the differences between models, it was possible to achieve common results in the Assessment Region 5, which is the region identified as the most complex. The construction of two new educational units of large capacities at centroids pop84 and pop46 seems to be satisfactory both for the condition of minimizing the average distance traveled by students, as for the condition to cover the greatest number of students within a distance of 1,500 meters.

Regarding the two models considered, the Capacitated p-Median problem model showed better applicability to the real case of locating Public Schools, because it has a capacity constraint that best represents the standard model for school construction defined by the Municipal Secretary of Education. However, this model does not ensure that the school is within a stated maximum distance from the school-age population.

The disadvantage of the CPMP model may be avoided by the MCLP model, because this latter model allows locating new public schools and ensuring the service to students who are within the distance of 1,500 meters from the nearest school. However, ensuring $100 \%$ of population service within the established radius can become quite costly, since a greater number of schools should be built while several would not use their full capacity. On the other hand, the MCLP model did not take into account the capacity constraint, making the results somehow distant from the present policy of the public education sector. In other words, if both criteria are imposed, i.e., if the CPMP model is applied and at the same time a distance limit of 1,500 meters is imposed then the number of new schools would be large, and operating costs for the municipality possibly beyond the possibilities established by the budget.

The use of two different models in this study showed the possibility of finding solutions common to both, that is, to find a solution that anticipates the expected demand while minimizing the 
distance traveled by the student. This feature ensures coverage of the greatest number of students in a given radius.

Overall, the study showed that there is a need for immediate expansion of the Childhood and Elementary Education Network in the Guaratiba Administrative Region. It seems necessary and recommended to elaborate a comprehensive project involving many specializations: a logistical planning for the location/ allocation of schools; application of pedagogical studies; expansion of the number of teachers and other supporting personnel; geographical and statistical studies to monitor the behavior of the population growth, and, finally, urban planning to allow the development of the infrastructure in the region studied.

\section{REFERENCES}

[1] Barcelos FB, Pizzolato ND \& Lorena LN. 2004. Localização de escolas de ensino fundamental com modelos capacitado e não-capacitado: Caso de Vitória/ES. Pesquisa Operacional, 24(1): 133-149.

[2] Current J, Daskin M \& Schilling D. 2002. Discrete network location models. In: Drezner Z \& HAMACHER HW. (Editors), Facility Location: Applications and Theory, Springer-Verlag Berlin Heidelberg New York.

[3] Beguin H, Deconnink J \& Peeters D. 1989. Optimizer la localization des ecoles primaires: Le cas de Mouscron, Belgique. Revue d'Economie Regionale et Urbaine, 5: 795-806.

[4] Brau L, Merce M \& Tarrago M. 1980. Manual de urbanismo. Barcelona, LeUMT, 2.

[5] Church R \& Revelle C. 1974. The maximal covering location problem. Papers of the Regional Science Association, 32: 101-118.

[6] Galvão RD, Espejo LGA \& Boffey B. 2002. A hierarchical model for the location of perinatal facilities in the Municipality of Rio de Janeiro. European Journal of Operational Research, 138: 495-517.

[7] IBGE. Instituto Brasileiro de Geografia e Estatística - IBGE, Censo 2000.

[8] Molinero CM. 1988. Schools in Southhampton: A quantitative approach to school location, closure and staffing. Journal of the Operational Research Society, 39(4): 339-350.

[9] Pizzolato ND, Barcelos FG \& Lorena LAN. 2004. School location methodology in urban areas of developing countries. International Transactions in Operations Research, 11: 667-681.

[10] Pizzolato ND, Raupp FMP \& Alzamora GS. 2012. Revisão de desafios aplicados em localização com base em modelos de p-medianas e suas variantes. Pesquisa Operacional para o Desenvolvimento, 4(1): 13-42.

[11] Pizzolato ND \& Silva HBF. 1997. The location of public schools: evaluation of practical experiences. International Transactions in Operations Research, 4(1): 13-22.

[12] RAHMAn SU \& SMith DK. 2002. Use of location-allocation models in health service development planning in developing nations. European Journal of Operational Research, 123: 437-452.

[13] Smith DK. 2008. A bibliography of applications of Operational Research in West Africa. International Journal of Operational Research, 15: 121-150. 
[14] SMith DK, HARPER PR \& POTTS CN. 2013. Bicriteria efficiency/equity hierarchical location models for public service application. Journal of the Operational Research Society, 64: 500-512.

[15] TEIXEIRA JC \& ANTUnes AP. 2008. A hierarchical location model for public facility planning. European Journal of Operations Research, 15(1): 92-104.

[16] TEWARI VK \& JENA S. 1987. High school location decision making in rural India and locationallocation models, in Spatial Analysis and Location-Allocation Models [edited by GHOSHAND A \& Rushton G.], New York: Van Nostrand Rheinhold.

[17] Viegas JM. 1987. Short and mid-term planning of an elementary school network in a suburb of Lisbon. Sistemi Urbani, 1: 57-77.

[18] White L, Smith H \& CURrie C. 2011. OR in developing countries: A review. European Journal of Operations Research, 208: 1-11.

[19] Yasenovskiy VS \& Hodgson MJ. 2007. Hierarchical location-allocation with spatial choice interaction modeling. Annals of the Association of American Geographers, 97: 496-511. 